Docente del Departamento Académico de Odontología Social. Facultad de Estomatología. Universidad Peruana Cayetano Heredia. Lima, Perú.

\title{
Propuesta del Modelo de Promoción y Prevención en Salud Oral en el Perú.
}

\section{Correspondencia}

Villavicencio-Caparó E. Propuesta del Modelo de Promoción y Prevención en Salud Oral en el Perú. Rev Estomatol Herediana. 2012; 22(1):65-66.

Ebingen Villavicencio

E-mail: ebingen@upch.pe

\section{Introducción}

El ser humano es creador de su realidad social que se traduce en su cultura, es creador de sus oportunidades y de sus problemas, en ese sentido el proceso salud enfermedad lejos de ser un evento probabilístico, además obedece a un modelo causal, donde la ciencia aplicada a la realidad (tecnología) podría jugar a favor de mantener sano al individuo. En salud oral este es el papel de la odontología basada en evidencias OBE, que según las últimas tendencias, busca disminuir la carga de enfermedad y/o secuelas de la misma, desde un enfoque de promoción, prevención y diagnóstico precoz.

Actualmente en el Perú, existe el modelo de Atención Integral de Salud basado en Familia y Comunidad, que toma el problema de salud oral como un objetivo sanitario y lo aborda de manera transversal mediante la Estrategia Sanitaria Nacional de Salud Bucal, pero no es suficiente, se necesita perfilar además un modelo que integre las acciones promocionales y preventivas en un modelo de programa nacional a fin de que las actividades (todas) estén articuladas entre ellas bajo un hilo conductor, que sea el "niño". Es decir el Perú merece tener un modelo, un paquete mínimo preventivo, que se le garantice a todos los niños, antes de que desarrollen caries o para prevenir nuevas caries.

Aplicando las técnicas de OBE, se propone un modelo peruano propio, en promoción y prevención en salud oral, donde el eje articulador sea el niño de 0 a 11 años y su riesgo de caries y/o el riesgo a nuevas caries.

\section{Estado del Arte}

En la actualidad la mejor evidencia disponible, respecto a promoción y prevención en salud oral sugiere:

Examen Estomatológico.- permite medir el riesgo de caries que tiene el paciente, diagnosticar precozmente los cambios estructurales en las superficies de los dientes, lo cual permite abordar con mínima intervención (1).

Instrucción de Higiene Oral.- La enseñanza de higiene y cepillado dental es una de las formas más efectivas de prevenir la caries den-

\begin{tabular}{|c|c|c|c|c|c|c|c|}
\hline $\begin{array}{c}\text { Edad en } \\
\text { Años }\end{array}$ & $\begin{array}{l}\text { Examen } \\
\text { Estomat. }\end{array}$ & $\begin{array}{c}\text { Instrucción } \\
\text { de higiene } \\
\text { oral }\end{array}$ & $\begin{array}{l}\text { Flúor } \\
\text { barniz }\end{array}$ & $\begin{array}{c}\text { Pasta con } \\
\text { flúor } 500 \\
\text { ppm }\end{array}$ & $\begin{array}{l}\text { Sellantes } \\
\text { de fisuras }\end{array}$ & $\begin{array}{l}\text { Pasta con } \\
\text { flúor } 1100 \\
\text { ppm }\end{array}$ & $\begin{array}{l}\text { Flúor fos- } \\
\text { fato acidu- } \\
\text { lado }\end{array}$ \\
\hline 0 & & & & & & & \\
\hline 1 & & & & & & & \\
\hline 2 & & & & & & & \\
\hline 3 & & & & & & & \\
\hline 4 & & & & & & & \\
\hline 5 & & & & & & & \\
\hline 6 & & & & & & & \\
\hline 7 & & & & & & & \\
\hline 8 & & & & & & & \\
\hline 9 & & & & & & & \\
\hline 10 & & & & & & & \\
\hline 11 & & & & & & & \\
\hline
\end{tabular}

Aplicación de Flúor Barniz.- La aplicación de flúor, de manera tópica, han demostrado reducir los índices de caries a nivel poblacional $(3,4,5)$.

Aplicación de Flúor Gel Fosfato Acidulado.- Protege químicamente al diente, poblacionalmente se ha evaluado que tiene un efecto de reducción de la caries de $18 \%$ a $22 \%$ (5-8).

Aplicación de Sellantes de Fosas $y$ Fisuras.- En estudios de seguimiento han demostrado tener un R.R. 0.48 a los 9 años de seguimiento y 0,74 en seguimiento de 23 meses (9).

\section{Propuesta.}

El modelo que se presenta a continuación, muestra las interven-

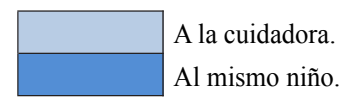


ciones en promoción y prevención a través de las diferentes edades desde los cero hasta los once años. Desde esta propuesta escalonada, el niño debe recibir flúor tópico en diferentes presentaciones, de acuerdo a su riesgo de caries y de acuerdo a su edad. El examen estomatológico debe darse cada 6 meses acompañado de la instrucción de higiene oral, la aplicación de realizarse cada 6 meses y la aplicación de sellantes debe estar circunscrita a la primera molar permanente, solo en caso de fosas y fisuras profundas.

Desde esta plataforma académica, se espera iniciar el debate, respecto al modelo de Promoción y Prevención en Salud Oral en el Perú.

Se deja la pregunta al lector: ¿En este esquema es necesario además adicionar, el consumo de sal fortificada con flúor?

\section{Referencias Bibliográficas}

1. Ditmyer M, Dounis G, Howard K, Mobley C, Cappelli D. Validation of a multifactorial risk factor model used for predicting future caries risk with nevada adolescents. BMC Oral Health. 2011; 11:18.
2. Twetman S, Topping G, Assaf A. Strong evidence that daily use of fluoride toothpaste prevents caries. EvidenceBased Dentristry. 2005; 6: 32.

3. De Sköld UM, Petersson LG, Lith A, Birkhed D. Effect of school-based fluoride varnish programmes on approximal caries in adolescents from different caries risk areas. Caries Res. 2005; 39:273-279.

4. Marinho V, Higgins J, Logan $S$, Sheiham A. Fluoride varnishes for preventing dental caries in children and adolescents. COCHRANE Database of Sistematyc Reviews, 2009; 1.

5. Poulsen S. Fluoride- Containing gels, mouth rinses and varnishes: An update of evidence of efficacy. European Archives of Paediatric Dentistry. 2009; 10(3): 157-161.

6. Lima-Chaves S, Viera-da- Silva L. As práticas preventivas no controle da cáries: a literature review. Cad. Saúde Pública. 2002;18(1) 129-139
7. Asociación Peruana de Odontología para Bebés. Acuerdos y recomendaciones de la mesa de Concertación 20072010. Lima: ASPOB; 2011.

8. Villena RS, Tenuta LM, Cury JA. Effect of AFP Gel Aplication Time on Enamel Demineralization and Fluoride Uptake In Situ. Braz Dent J. 2009; 20 (1): 37-41.

9. Hiri A. Pit and Fissure Sealants Versus Fluoride Varnishes for preventing dental decay in children and adolescents. COCHRANE Database Sysmemic Review. 2010; 3. 